\title{
An RBC model with investment-specific technological change: Lessons for Bulgaria (1999-2018)
}

\author{
Aleksandar Vasilev*
}

August 7, 2019

\begin{abstract}
We introduce investment-specific technological change (ISTC) into an otherwise standard real-business-cycle setup with a government sector. We calibrate the model to Bulgarian data for the period following the introduction of the currency board arrangement (1999-2018). We then investigate the quantitative importance of the ISTC process in such a model for cyclical fluctuations in Bulgaria, and compare the results to a setup where cycles are driven by shocks to total factor productivity. We find that the model with ISTC shocks matches Bulgarian data better than the standard model driven by changes to total factor productivity only. The ISTC process is thus a better candidate for a a "technology shock generation process," at least in Bulgaria since the 2000s.
\end{abstract}

Keywords: business cycles, investment-specific technology change, Bulgaria

JEL Classification Codes: E24, E32

${ }^{*}$ Lecturer, Lincoln International Business School, UK. E-mail for correspondence: AVasilev@lincoln.ac.uk. 


\section{Introduction and Motivation}

The benchmark real-business-cycle (RBC) model assumes that the major shocks affecting the economy are the ones working through the "total factor productivity" factor in the aggregate production function. Furthermore, in the case of a Cobb-Douglas specification, which is often utilized in the literature, such a technological change is referred to as "neutral," as it affects in the same way both the physical capital stock and labor services, and thus is not biased towards any of the two production inputs. In addition, in the standard RBC setup, physical capital is also assumed to be homogeneous. In other words, each unit of the capital "good" is equally productive, independent of its date of manufacture. This is a rather strong theoretical assumption, as in reality physical capital from older vintages is less productive, and thus also less valuable.

In order to investigate the aggregate effects caused by the usage of capital from different vintages in the production process, we will relax the assumption that physical capital is homogeneous. In addition, we will no longer consider total factor productivity changes as being the main driving force behind the observed business cycles in the economy, and instead will focus on the biased, or investment-specific technological progress mentioned above. After all, the new technology is usually already embodied in the new units of capital, which is especially true for equipment in sectors such as transportation, telecommunications, finance, IT, among others, where newer vintages of capital are much more productive.

In the RBC literature, Dynamic Stochastic General Equilibrium (DSGE) setups augmented with investment-specific technological change (ISTC) process have already been used, mostly in the context of Western economies, to quantify the contribution to long-run productivity growth of the different sources of technical progress. Examples of such micro-founded studies include Greenwood et al. (2000), Kiley (2001), Cummins and Violante (2002), Pakko (2002, 2005), Carlaw and Kosempel (2004), Bakhshi and Larsen (2005), Martinez et al. (2008, 2010), Rodriguez and Torres (2012), among many others. In addition, Greenwood et al. (2000) investigate the quantitative effects of ISTC shocks for the business cycles in the US. They find that a third of output volatility is caused by such shocks, a result confirmed and extended later in Cummins and Violante (2002). Based on those models, Fisher (2006) 
later proposed an identification scheme to disentangle the empirical effect of TFP vs. ISTC shocks, namely that in the long run the relative price of investment is affected by ISTC shocks only. Depending on the period, he finds the latter to explain between $42-67$ percent of output variability in the US, depending on the particular period studied. ${ }^{1}$

Conditional on accepting the statement that not all units of physical capital are the same as a factual one, we can then argue that the case of Bulgaria, a new member state of the European Union (EU), could provide us with some novel insights regarding the true driving force of business cycle fluctuations observed in the Eastern European economies. In the 1990s, due to the implementation of earlier 5-year central plans, this former transition economy (like many others) found itself with an excess of "old" capital, characterized by a very low market value. At the same time the emerging market economy felt a scarcity of (and thus an excess demand for-) "new," high-value market capital. The last two decades thus correspond to a period when Bulgaria was rapidly developing by fundamentally restructuring its economy by accumulating modern capital in order to reflect the new market reality, which was based on improvements in labor productivity, a development trajectory which eventually led to Bulgaria's accession into the EU. This path of economic development was only possible through trade, which allowed for valuable physical capital from the West to be imported. ${ }^{2}$ Bulgaria will thus serve as a good testing case for the theory of business cycles driven by investment-specific technological change.

In this paper we will therefore consider an alternative "technology shock" propagation mechanism, or more specifically, the investment-specific technological change (ISTC) process into a DSGE framework, and quantitatively investigate the possibility that this process is the actual driving force responsible for the observed business cycle fluctuations in Bulgaria. To this end, we calibrate the model to Bulgarian data for the period following the introduction of the currency board arrangement (1999-2018), and also compare the results obtained to those generated by the standard setup where cycles are driven by shocks to total factor

\footnotetext{
${ }^{1}$ Other econometric papers addressing the determinants of macroeconomic volatility include Arias et al. (2007), Basu et al. (2006), Justiniano and Primiceri (2008), Justiniano et al. (2011), Molinari et al. (2013).

${ }^{2}$ At the same time, the post 1990s period was a time that featured explosion in information and communication technologies (ICT), which was also scarce in Bulgaria at the time.
} 
productivity only. We find that the investment-specific shock process helps match Bulgarian data better than the standard model with neutral technological progress alone. This is a new and interesting result for Bulgaria, as it provides researchers with a robust theoretical basis, which is able to breaks the observational equivalence behind the observed output volatility, and in turn say something about the possible drivers of business cycle fluctuations in data. In addition, the ISTC model provides an alternative transmission mechanism able to propagating economic fluctuations of the same magnitude as the ones observed in Bulgaria over the period studied.

The rest of the paper is organized as follows: Section 2 describes the model framework and characterizes the decentralized competitive equilibrium system, Section 3 discusses the calibration procedure, and Section 4 documents the steady-state model solution. Sections 5 proceeds with the out-of-steady-state dynamics of model variables, and compares the simulated second moments of theoretical variables against their empirical counterparts. Section 6 then concludes the paper.

\section{Model Description}

There is a representative household, which derives utility out of consumption and leisure. The time available to the household can be either spent in productive use, or enjoyed as leisure. The government taxes final consumption spending, and in addition levies a common proportional ("flat") tax on labor and capital income. The revenue raised is then used to finance purchases of government consumption goods, and government transfers. On the production side, there is a representative firm, which hires labor services and physical capital to produce a homogeneous final good, which could in turn be used for consumption, investment, or government purchases.

\section{$2.1 \quad$ Households}

There is a representative household, which maximizes its expected utility function

$$
\max _{\left\{c_{t}, h_{t}, i_{t}, k_{t+1}\right\}_{t=0}^{\infty}} E_{0} \sum_{t=0}^{\infty} \beta^{t}\left\{\ln c_{t}+\gamma \ln \left(1-h_{t}\right)\right\},
$$


where $E_{0}$ denotes household's expectations as of period $0, c_{t}$ denotes household's private consumption in period $t, h_{t}$ refers to hours worked in period $t, 0<\beta<1$ is the discount factor, and $\gamma>0$ is the relative weight that the household attaches to leisure. ${ }^{3}$ The time endowment available to the household in each time period is normalized to unity.

The household starts with an initial stock of physical capital $k_{0}>0$, and has to decide how much to add to it in the form of new investment. As in Greenwood et al. $(1988,1997)$, the productivity $Z_{t}$ of new investment is time varying. Note that when $Z_{t}=1, \forall t$, the setup collapses to the standard setup.

The law of motion for physical capital is described by the following dynamic equation:

$$
k_{t+1}=Z_{t} i_{t}+(1-\delta) k_{t},
$$

where $0<\delta<1$ is the depreciation rate. Alternatively, the level of investment in each time period can be expressed as

$$
i_{t}=\frac{k_{t+1}-(1-\delta) k_{t}}{Z_{t}}
$$

Note that the higher $Z_{t}$, the larger the quality of capital, or the more valuable new capital stock is. ${ }^{4}$

Next, the real interest rate is $r_{t}$, hence the before-tax capital income of the household in period $t$ equals $r_{t} k_{t}$. In addition to capital income, the household can generate labor income; Hours supplied to the representative firm are rewarded at the hourly wage rate of $w_{t}$, so

\footnotetext{
${ }^{3}$ This relatively standard utility function is equivalent to a specification with a separable term containing government consumption, e.g. Baxter and King (1993). Since in this paper we focus on the exogenous (observed) fiscal policies, and the household takes government spending as given, the presence of such a term makes no difference for the results obtained in this paper. For the sake of brevity, we skip this term in the utility representation above.

${ }^{4}$ Alternatively, an increase in $Z_{t}$ can be mapped into a positive technological shock, as it allows for a cheaper transformation from consumption to investment. In other words, it makes producing investment goods cheaper relative to consumption goods. That is why in practice statisticians use so-called "hedonic prices" (Gordon 1990, Cummins and Violante 2002) to adjust capital stock for quality in order to make sensible comparisons.
} 
pre-tax labor income equals $w_{t} h_{t}$. Lastly, the household owns the firm in the economy and has a legal claim on all the firm's profit, $\pi_{t}$.

Next, the household's problem can be now simplified to

$$
\max _{\left\{c_{t}, h_{t}, i_{t}, k_{t+1}\right\}_{t=0}^{\infty}} E_{0} \sum_{t=0}^{\infty} \beta^{t}\left\{\ln c_{t}+\gamma \ln \left(1-h_{t}\right)\right\}
$$

s.t.

$$
\left(1+\tau^{c}\right) c_{t}+\frac{k_{t+1}-(1-\delta) k_{t}}{Z_{t}}=\left(1-\tau^{y}\right)\left[w_{t} h_{t}+r_{t} k_{t}+\pi_{t}\right]+g_{t}^{t}
$$

where where $\tau^{c}$ is the tax on consumption, $\tau^{y}$ is the proportional income tax rate on both labor and capital $\left(0<\tau^{c}, \tau^{y}<1\right)$, and $g_{t}^{t}$ denotes lump-sum government transfers. The household takes the tax rates $\left\{\tau^{c}, \tau^{y}\right\}$, government spending categories, $\left\{g_{t}^{c}, g_{t}^{t}\right\}_{t=0}^{\infty}$, firm's profit $\left\{\pi_{t}\right\}_{t=0}^{\infty}$, the realized values of the two technology processes $\left\{A_{t}, Z_{t}\right\}_{t=0}^{\infty}$, input prices $\left\{w_{t}, r_{t}\right\}_{t=0}^{\infty}$, and chooses allocation sequences $\left\{c_{t}, h_{t}, k_{t+1}\right\}_{t=0}^{\infty}$ to maximize its inter-temporal utility subject to the budget constraint. ${ }^{5}$

The first-order optimality conditions as as follows:

$$
\begin{aligned}
c_{t} & : \frac{1}{c_{t}}=\lambda_{t}\left(1+\tau^{c}\right) \\
h_{t} & : \frac{\gamma}{1-h_{t}}=\lambda_{t}\left(1-\tau^{y}\right) w_{t} \\
k_{t+1} & : \frac{\lambda_{t}}{Z_{t}}=\beta E_{t} \lambda_{t+1}\left[\frac{1-\delta}{Z_{t+1}}+\left(1-\tau^{y}\right) r_{t+1}\right] \\
T V C & : \lim _{t \rightarrow \infty} \beta^{t} \lambda_{t} k_{t+1}=0
\end{aligned}
$$

where $\lambda_{t}$ is the Lagrangean multiplier attached to household's budget constraint in period t. The interpretation of the first-order conditions above is as follows: the first equation states that for each household, the marginal utility of consumption equals the marginal utility of wealth, corrected for the consumption tax rate. The second equation states that when choosing labor supply optimally, at the margin, the household balances the benefit from working in terms of additional income generated, against the cost measured in terms of lower

\footnotetext{
${ }^{5}$ Note that conditional on the realization of $\left\{Z_{t}\right\}_{t=0}^{\infty}$, by choosing next-period capital stock, $k_{t+1}$, the household effectively determines the optimal level of investment $i_{t}$ in each period.
} 
utility of leisure. The third equation is the so-called "Euler condition," which describes how the household chooses to allocate physical capital over time, after taking into consideration the level of the investment-specific technological change as well. The last condition is called the "transversality condition" (TVC): it states that at the end of the horizon, the value of physical capital should be zero.

\subsection{Firm problem}

There is a representative firm in the economy, which produces a homogeneous final product. The price of firm's output is normalized to unity. The production technology is assumed to be Cobb-Douglas and uses both physical capital, $k_{t}$, and labor hours, $h_{t}$, to maximize static profit $^{6}$

$$
\Pi_{t}=A_{t} k_{t}^{\alpha} h_{t}^{1-\alpha}-r_{t} k_{t}-w_{t} h_{t}
$$

where $A_{t}$ denotes the level of total factor productivity in period $t$. In equilibrium, there are no profits, or $\pi_{t}=0, \forall t$, and each input is priced according to its marginal product, i.e.:

$$
\begin{aligned}
& k_{t}: \alpha \frac{y_{t}}{k_{t}}=r_{t}, \\
& h_{t}:(1-\alpha) \frac{y_{t}}{h_{t}}=w_{t} .
\end{aligned}
$$

\subsection{Government}

In the model setup, the government is levying taxes on labor and capital income, as well as consumption, in order to finance its spending on government purchases, and government transfers. ${ }^{7}$ The government period- $t$ budget constraint is as follows:

$$
g_{t}^{c}+g_{t}^{t}=\tau^{c} c_{t}+\tau^{y}\left[w_{t} h_{t}+r_{t} k_{t}+\pi_{t}\right]
$$

Income tax rate and government consumption-to-output ratio would be chosen to match their average values in data. Finally, government transfers would be determined residually in each period so that the government budget is always balanced.

\footnotetext{
${ }^{6}$ Since the firm rents the capital from households, the problem of the firm is a sequence of static profitmaximizing problems.

${ }^{7}$ For simplicity, we assume that the government cannot issue debt.
} 


\subsection{Exogenous stochastic processes}

The exogenous processes for total factor productivity, $A_{t}$, and ISTC, $Z_{t}$, will be assumed to follow $\mathrm{AR}(1)$ processes in natural logarithms:

$$
\begin{aligned}
& \ln A_{t+1}=\left(1-\rho_{a}\right) \ln A+\rho_{a} \ln A_{t}+\epsilon_{t+1}^{a} \\
& \ln Z_{t+1}=\left(1-\rho_{z}\right) \ln Z+\rho_{z} \ln Z_{t}+\epsilon_{t+1}^{z},
\end{aligned}
$$

where $A, Z$ denote the steady-state values of the two processes, $0<\rho_{a}, \rho_{z}<1$ are the respective persistence parameters, and the productivity innovations and changes to institutional quality are drawn from the following distributions: $\epsilon_{t}^{a} \sim i . i . d N\left(0, \sigma_{a}^{2}\right)$ and $\epsilon_{t}^{z} \sim i . i . d N\left(0, \sigma_{z}^{2}\right)$, respectively.

\subsection{Dynamic Competitive Equilibrium (DCE)}

For the given processes followed by the two technologies $\left\{A_{t}, Z_{t}\right\}_{t=0}^{\infty}$, tax rates $\left\{\tau^{c}, \tau^{y}\right\}$, and initial capital stock $\left\{k_{0}\right\}$, the decentralized dynamic competitive equilibrium is a list of private allocations $\left\{c_{t}, i_{t}, k_{t}, h_{t}\right\}_{t=0}^{\infty}$, a sequence of government purchases and transfers

$\left\{g_{t}^{c}, g_{t}^{t}\right\}_{t=0}^{\infty}$, and input prices $\left\{w_{t}, r_{t}\right\}_{t=0}^{\infty}$ such that (i) the household maximizes its utility function subject to its budget constraint; (ii) the representative firm maximizes profit; (iii) the government balances its budget in each period; (iv) all markets clear.

\section{Data and Model Calibration}

To characterize business cycle fluctuations in Bulgaria, we will focus on the period following the introduction of the currency board (1999-2018). Quarterly data on output, consumption and investment was collected from the National Statistical Institute (2019), while the real interest rate is taken from Bulgarian National Bank Statistical Database (2019). The calibration strategy described in this section follows a long-established tradition in modern macroeconomics: first, as in Vasilev (2016), the discount factor, $\beta=0.982$, is set to match the steady-state capital-to-output ratio in Bulgaria, $k / y=13.964$, in the steady-state Euler equation. The labor share parameter, $1-\alpha=0.571$, is obtained as in Vasilev (2017d), and equals the average value of labor income in aggregate output over the period 1999-2016. This value is slightly higher as compared to other studies on developed economies, due to 
the over-accumulation of physical capital, which, as discussed in the introduction, was part of the ideology of the totalitarian regime and the central planning, which was in place until 1989. Next, the average labor and capital income tax rate was set to $\tau^{y}=0.1$. This is the average effective tax rate on income between 1999-2007, when Bulgaria used progressive income taxation, and equal to the proportional income tax rate introduced as of 2008, and still in place as of today. Similarly, the average tax rate on consumption is set to its value over the period, $\tau^{c}=0.2$.

Next, the relative weight attached to the utility out of leisure in the household's utility function, $\gamma$, is calibrated to match that in steady-state consumers would supply one-third of their time endowment to working. This is in line with the estimates for Bulgaria (Vasilev 2017a) as well over the period studied. Next, the depreciation rate of physical capital in Bulgaria, $\delta=0.013$, was taken from Vasilev (2016). It was estimated as the average quarterly depreciation rate over the period 1999-2014. Finally, the process followed by TFP, is estimated from the detrended series by running an $\mathrm{AR}(1)$ regression specification and saving the residuals obtained. Due to data limitations, we follow Torres (2013), and use the same moments for the ISTC process as well. ${ }^{8}$ In that way, the comparison between the two different transmission channels of technology shocks is more tractable as well. Table 1 on the next page summarizes the values of all model parameters used in the paper.

\section{Steady-State}

Once the values of model parameters were obtained, the steady-state equilibrium system solved, the "big ratios" can be compared to their averages in Bulgarian data. The results are reported in Table 2 on the next page. The steady-state level of output was normalized to unity (hence the level of technology $A$ differs from one, which is usually the normalization done in other studies), which greatly simplified the computations. Next, the model matches consumption-to-output and government purchases ratios by construction; The investment ratios are also closely approximated, despite the closed-economy assumption and the absence

\footnotetext{
${ }^{8}$ This is not a restrictive assumption, as shown in studies such as Greenwood et al. (2000) and Pakko (2005) for the US, and Rodriguez and Torres (2010) for the US, Germany, and Japan. Those authors also assume that the two technological processes are independent.
} 
Table 1: Model Parameters

\begin{tabular}{llll}
\hline \hline Parameter & Value & Description & Method \\
\hline$\beta$ & 0.982 & Discount factor & Calibrated \\
$\alpha$ & 0.429 & Capital Share & Data average \\
$1-\alpha$ & 0.571 & Labor Share & Calibrated \\
$\gamma$ & 0.873 & Relative weight attached to leisure & Calibrated \\
$\delta$ & 0.013 & Depreciation rate on physical capital & Data average \\
$\tau^{y}$ & 0.100 & Average tax rate on income & Data average \\
$\tau^{c}$ & 0.200 & VAT/consumption tax rate & Data average \\
$\rho_{a}$ & 0.701 & AR(1) persistence coefficient, TFP process & Estimated \\
$\sigma_{a}$ & 0.044 & st. error, TFP process & Estimated \\
$\rho_{z}$ & 0.701 & AR(1) persistence coefficient, ISTC process & Set \\
$\sigma_{z}$ & 0.044 & st. error, ISTC process & Set \\
\hline
\end{tabular}

of foreign trade sector. The shares of labor and capital income are also identical to those in data, which is an artefact of the assumptions imposed on functional form of the aggregate production function. The after-tax return, where $\bar{r}=\left(1-\tau^{y}\right) r-\delta$ is also relatively wellcaptured by the model. Lastly, given the absence of government-issued debt, and the fact that government transfers were chosen residually to balance the government budget in each time period, the result along this dimension is understandably not so close to the average ratio in data.

\section{Out of steady-state model dynamics}

Since the model does not have an analytical solution for the equilibrium behavior of variables outside their steady-state values, we need to solve the model numerically. This is done by loglinearizing the original equilibrium (non-linear) system of equations around the steady-state. This transformation produces a first-order system of stochastic difference equations, which is a good approximation for the original non-linear system. We proceed to study the dynamic behavior of model variables to an isolated shock to the total factor productivity process, and the responses to a ISTC shock. Next, we fully simulate the model to compare how the 
Table 2: Data Averages and Long-run Solution

\begin{tabular}{llll}
\hline \hline Variable & Description & Data & Model \\
\hline$y$ & Steady-state output & N/A & 1.000 \\
$c / y$ & Consumption-to-output ratio & 0.648 & 0.674 \\
$i / y$ & Investment-to-output ratio & 0.201 & 0.175 \\
$k / y$ & Capital-to-output ratio & 13.96 & 13.96 \\
$g^{c} / y$ & Government consumption-to-output ratio & 0.151 & 0.151 \\
$w h / y$ & Labor income-to-output ratio & 0.571 & 0.571 \\
$r k / y$ & Capital income-to-output ratio & 0.429 & 0.429 \\
$h$ & Share of time spent working & 0.333 & 0.333 \\
$\bar{r}$ & After-tax net return on capital & 0.014 & 0.016 \\
\hline
\end{tabular}

second moments of the model perform when compared against their empirical counterparts when there is only one type of shock hitting the economy, as well as when both shocks are jointlt at play.

\subsection{Impulse Response Analysis}

This subsection documents the impulse responses of model variables to a $1 \%$ surprise innovation to each of the two types of technology in the model. The impulse response functions (IRFs) are presented in Fig. 1 and Fig. 2 for the TFP and ISTC shocks, respectively. As a result of the one-time unexpected positive shock to total factor productivity, output increases upon impact. This expands the availability of resources in the economy, so used of output consumption, investment, and government consumption - also increase contemporaneously. At the same time, the increase in total factor productivity increases the after-tax return on the two factors of production, labor and capital. The representative household then responds to the incentives contained in prices and start accumulating capital, and rents more labor services to the firm. In turn, the increase in capital input feeds back in output through the production function and that further adds to the positive effect of the TFP shock. In the labor market, the wage rate increases, and the household increases its hours worked accordingly. In turn, the increase in total hours further increases output, again in an indirect 

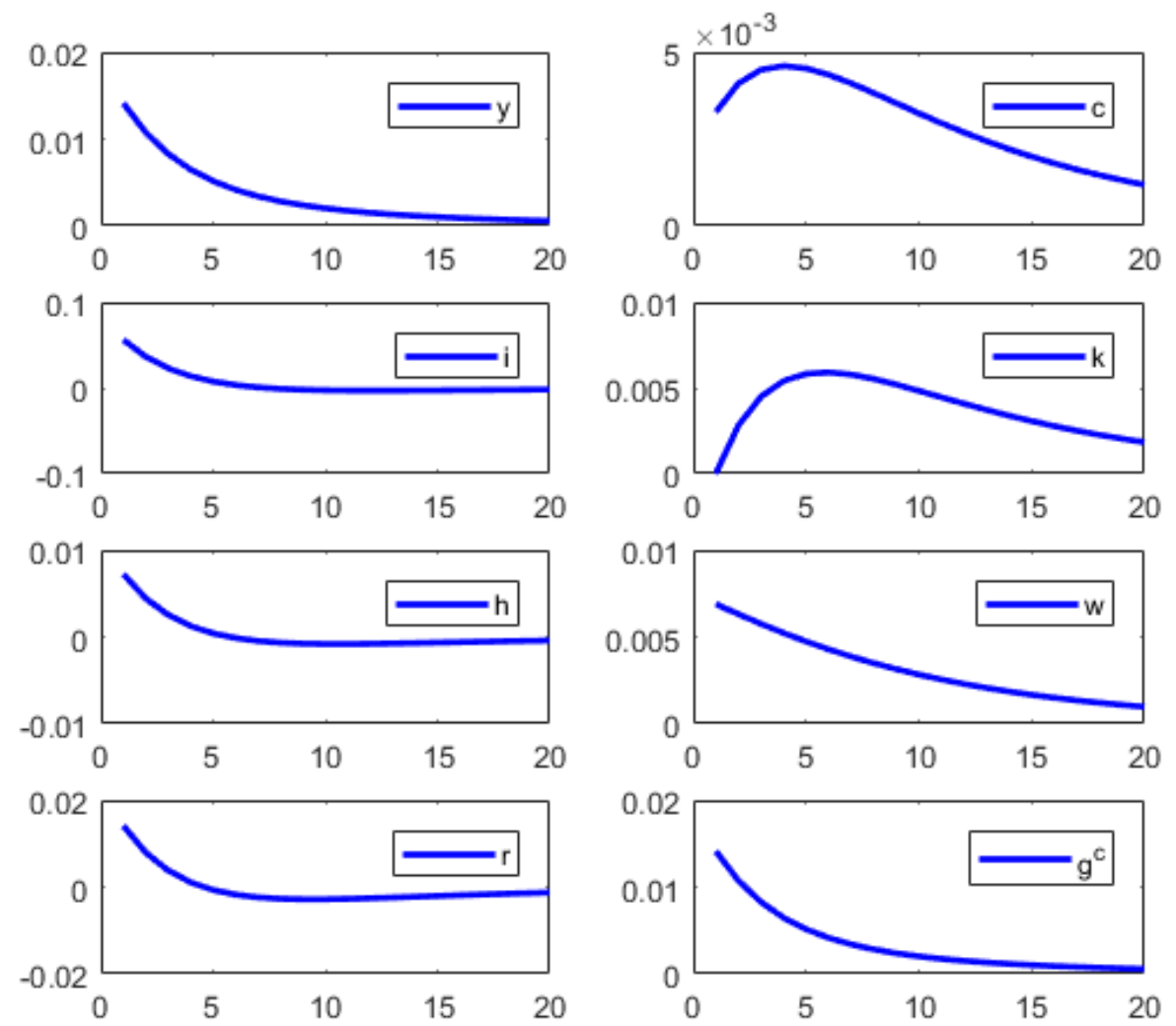

Figure 1: Impulse Responses to a 1\% surprise innovation in technology(TFP)

manner.

Over time, as physical capital is being accumulated, the diminishing returns cause its aftertax marginal product to decrease, which in turn diminishes the household's incentive to save. As a result, the physical capital stock eventually returns to its steady-state, and thus exhibits a hump-shaped dynamics over its transition path. The rest of the model variables return to their old steady-states in a monotone fashion as the effect of the one-time surprise innovation in TFP dies out.

In contrast, the dynamic responses of model variables to an unexpected positive $1 \%$ shock to the ISTC process presented in Fig. 2 on the next page differ from the TFP case above, mostly in the behavior of consumption and factor prices. For one, the effect on consumption 

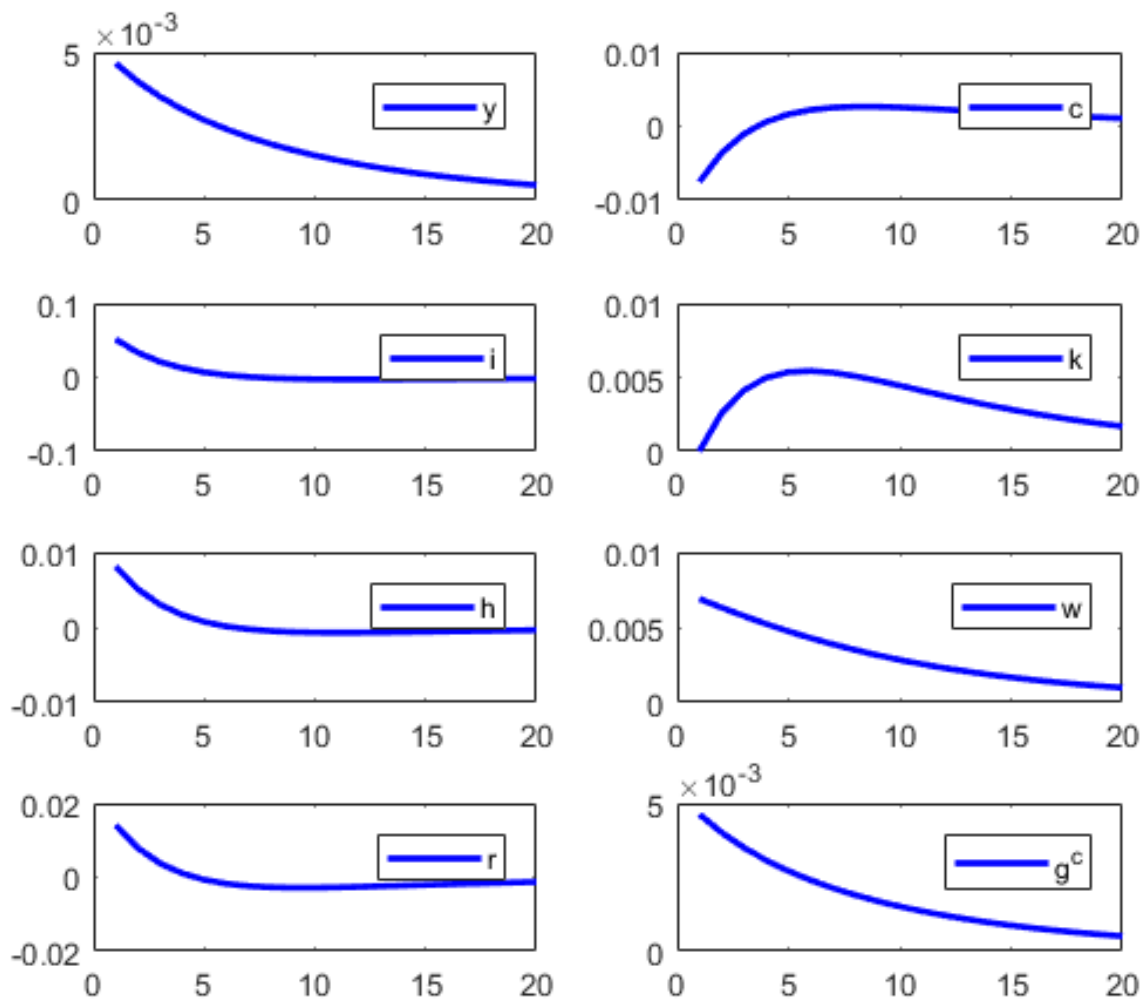

Figure 2: Impulse Responses to a 1\% surprise innovation in technology (ISTC)

is negative upon impact, which is because the shock makes new investment more profitable. In other words, the productivity of newer vintages of capital is higher than that of the already installed physical capital; as a result, there is a substitution away from consumption and towards more saving. The increase in investment in turn leads to an increase in capital. In addition, the ISTC shock makes investment cheaper relative to consumption, which triggers both an intertemporal substitution effect, causing an increase in current saving while postponing current consumption, as well as an intra-temporal substitution between current consumption and leisure enjoyed in the same time period. More specifically, the increase in capital productivity motivates the worker to supply more hours of labor, as now the wage rate is higher.

Over time, similar to the TFP case, as new physical capital is being accumulated, diminish- 
ing returns to this factor of production eventually cause its after-tax marginal product to decrease, which in turn diminishes the households' incentives to save. As a result, physical capital stock eventually returns to its steady-state value, and its trajectory features a humpshaped dynamics over its transition path. The rest of the model variables return to their old steady-states in a monotone fashion as the effect of the one-time surprise innovation in the ISTC process dies out. Note that just by looking at the response of output, an econometrician will not be able to distinguish between TFP and ISTC shocks. Researchers should look at the responses of other variables, such as consumption and labor supply. By looking at a wider set of statistic, one would be able to break the so-called "observational equivalence" and determine which type of shocks drive the business cycle. We investigate this further in the following section.

\subsection{Simulation and moment-matching}

As in Vasilev (2017b), we will now simulate the model 10,000 times for the length of the data horizon. This large number of simulations is performed to minimize the sample error, when we average out the results. Both empirical and model-simulated data is detrended using the Hodrick-Prescott (1980) filter. Table 3 on the next page summarizes the second moments of data (relative volatilities to output, and contemporaneous correlations with output) versus the same moments computed from the model-simulated data at quarterly frequency. ${ }^{9}$ In addition, to minimize the sample error, the simulated moments are averaged out over the computer-generated draws. As in Vasilev (2016, 2017b, 2017c), all models match quite well the absolute volatility of output. Next, by construction, government consumption in the model varies as much as output in all the three specifications. In addition, the predicted consumption and investment volatilies across models are too high relative to data. Still, the models are all qualitatively consistent with the stylized fact that consumption generally varies less than output, while investment is more volatile than output.

With respect to the labor market variables, the variability of employment predicted by the ISTC model is equal to that in data, and this is one of the margins where the ISTC spec-

\footnotetext{
${ }^{9}$ The "ISTC only" is the case with ISTC shocks only, while the "TFP only" is the benchmark setup with TFP shocks only in the economy. "Both shocks" is the case when the two types of shocks are at play.
} 
Table 3: Business Cycle Moments

\begin{tabular}{lllll}
\hline \hline & Data & ISTC only & TFP only & Both shocks \\
\hline$\sigma_{y}$ & 0.05 & 0.05 & 0.05 & 0.05 \\
$\sigma_{c} / \sigma_{y}$ & 0.55 & 0.91 & 0.82 & 0.83 \\
$\sigma_{i} / \sigma_{y}$ & 1.77 & 3.32 & 2.35 & 2.59 \\
$\sigma_{g} / \sigma_{y}$ & 1.21 & 1.00 & 1.00 & 1.00 \\
$\sigma_{h} / \sigma_{y}$ & 0.63 & 0.63 & 0.28 & 0.38 \\
$\sigma_{w} / \sigma_{y}$ & 0.83 & 0.84 & 0.86 & 0.84 \\
$\sigma_{y / h} / \sigma_{y}$ & 0.86 & 0.84 & 0.86 & 0.84 \\
\hline $\operatorname{corr}(c, y)$ & 0.85 & 0.46 & 0.90 & 0.78 \\
$\operatorname{corr}(i, y)$ & 0.61 & 0.62 & 0.83 & 0.76 \\
$\operatorname{corr}(g, y)$ & 0.31 & 1.00 & 1.00 & 1.00 \\
$\operatorname{corr}(h, y)$ & 0.49 & 0.55 & 0.59 & 0.53 \\
$\operatorname{corr}(w, y)$ & -0.01 & 0.43 & 0.96 & 0.91 \\
\hline
\end{tabular}

ification dominates the TFP model; the variability of wages in both models is also very close to the volatility documented in data. This result is able to solve the labor-market puzzle in the RBC literature; more specifically, that the TFP model with the perfectlycompetitive assumption, e.g. Vasilev (2009), as well as here, is not able to describe very well the dynamics of labor market variables. In contrast, note that the ISTC model is able to rationalize labor market dynamics without departing from the perfectly-competitive paradigm.

Next, in terms of contemporaneous correlations, the ISTC model also matches quite well the pro-cyclicality of investment and hours (but underestimates consumption co-movement with output), while the TFP model systematically over-predicts the co-movement of the main aggregate variables - consumption, investment, and government consumption; This, however, is a common limitation of this class of RBC models. With respect to the acyclicality of wages in data, the ISTC model again dominates the TFP model, as the former predicts a moderate pro-cyclicality, while the latter generates a strong co-movement with output. ${ }^{10}$

\footnotetext{
${ }^{10}$ This shortcoming is well-known in the literature and an artefact of the wage being equal to the labor productivity in the model, which is a modelling assumption that is independent of the source of the technology
} 
In the next subsection, as in Vasilev (2017b), we investigate the dynamic correlation between labor market variables at different leads and lags, thus evaluating how well the model matches the phase dynamics among variables. In addition, the auto-correlation functions (ACFs) of empirical data, obtained from an unrestricted VAR(1) model are put under scrutiny and compared and contrasted to the simulated counterparts generated from the theoretical model with shocks to the ISTC process.

\subsection{Auto- and cross-correlation}

This subsection discusses the auto-(ACFs) and cross-correlation functions (CCFs) of the major model variables. The coefficients of empirical ACFs and CCFs at different leads and lags are presented in Table 4 below against the averaged simulated AFCs and CCFs. ${ }^{11}$ For the sake of economizing space, we present results only for ISTC case below. ${ }^{12}$

As seen from Table 4 on the next page, the ISTC model compares relatively well vis-a-vis data, where $u_{t}=1-n_{t}$ denotes unemployment. Empirical ACFs for output and investment are slightly outside the confidence band predicted by the model, while the ACFs for total factor productivity and household consumption are well-approximated by the model. The persistence of labor market variables are also relatively well-described by the model dynamics. Overall, the ISTC model generates too much persistence in output and both employment and unemployment, and is subject to the criticism expressed in Nelson and Plosser (1992), Cogley and Nason (1995) and Rotemberg and Woodford (1996b), who all argue that the RBC class of models does not have a strong internal propagation mechanism besides the strong persistence in the TFP process. In those models, e.g. Vasilev (2009), and in the benchmark case presented in this paper, labor market is modelled in the Walrasian market-clearing spirit, and output and unemployment persistence is low.

\footnotetext{
innovations used in the setup.

${ }^{11}$ Following Canova (2007), this exercise is used as a goodness-of-fit measure.

${ }^{12}$ The results for the standard (TFP) case, and those from the combined model are available upon request.
} 
Table 4: Autocorrelations for Bulgarian data and the model economy

\begin{tabular}{|c|c|c|c|c|c|}
\hline & & $\mathrm{k}$ & & & \\
\hline Method & Statistic & 0 & 1 & 2 & 3 \\
\hline Data & $\operatorname{corr}\left(u_{t}, u_{t-k}\right)$ & 1.000 & 0.765 & 0.552 & 0.553 \\
\hline ISTC Model & $\operatorname{corr}\left(u_{t}, u_{t-k}\right)$ & 1.000 & 0.952 & 0.893 & 0.824 \\
\hline & (s.e.) & $(0.000)$ & $(0.030)$ & $(0.057)$ & $(0.083)$ \\
\hline Data & $\operatorname{corr}\left(n_{t}, n_{t-k}\right)$ & 1.000 & 0.484 & 0.009 & 0.352 \\
\hline ISTCModel & $\operatorname{corr}\left(n_{t}, n_{t-k}\right)$ & 1.000 & 0.952 & 0.893 & 0.824 \\
\hline & (s.e.) & $(0.000)$ & $(0.030)$ & $(0.057)$ & $(0.083)$ \\
\hline Data & $\operatorname{corr}\left(y_{t}, y_{t-k}\right)$ & 1.000 & 0.810 & 0.663 & 0.479 \\
\hline ISTC Model & $\operatorname{corr}\left(y_{t}, y_{t-k}\right)$ & 1.000 & 0.958 & 0.909 & 0.852 \\
\hline & (s.e.) & $(0.000)$ & $(0.025)$ & $(0.049)$ & $(0.071)$ \\
\hline Data & $\operatorname{corr}\left(a_{t}, a_{t-k}\right)$ & 1.000 & 0.702 & 0.449 & 0.277 \\
\hline ISTC Model & $\operatorname{corr}\left(a_{t}, a_{t-k}\right)$ & 1.000 & 0.955 & 0.901 & 0.838 \\
\hline & (s.e.) & $(0.000)$ & $(0.027)$ & $(0.053)$ & $(0.076)$ \\
\hline Data & $\operatorname{corr}\left(c_{t}, c_{t-k}\right)$ & 1.000 & 0.971 & 0.952 & 0.913 \\
\hline ISTC Model & $\operatorname{corr}\left(c_{t}, c_{t-k}\right)$ & 1.000 & 0.955 & 0.900 & 0.837 \\
\hline & (s.e.) & $(0.000)$ & $(0.028)$ & $(0.053)$ & $(0.077)$ \\
\hline Data & $\operatorname{corr}\left(i_{t}, i_{t-k}\right)$ & 1.000 & 0.810 & 0.722 & 0.594 \\
\hline ISTC Model & $\operatorname{corr}\left(i_{t}, i_{t-k}\right)$ & 1.000 & 0.953 & 0.894 & 0.826 \\
\hline & (s.e.) & $(0.000)$ & $(0.027)$ & $(0.057)$ & $(0.082)$ \\
\hline Data & $\operatorname{corr}\left(w_{t}, w_{t-k}\right)$ & 1.000 & 0.760 & 0.783 & 0.554 \\
\hline ISTC Model & $\operatorname{corr}\left(w_{t}, w_{t-k}\right)$ & 1.000 & 0.957 & 0.906 & 0.848 \\
\hline & (s.e.) & $(0.000)$ & $(0.026)$ & $(0.050)$ & $(0.072)$ \\
\hline
\end{tabular}

Next, as seen from Table 5 on the next page, over the business cycle, in data labor productivity leads employment. The model, however, cannot account for this fact. As in the standard RBC model, an ISTC technology shock can be regarded as a factor shifting the labor demand curve, while holding the labor supply curve constant. Therefore, the generated effect between employment and labor productivity in the model is only a contemporaneous one, which is not what is observed in data: In fact, wages lead hours by two periods in 
Bulgarian economy over the period 1999-2018.

Table 5: Dynamic correlations for Bulgarian data and the model economy

\begin{tabular}{|c|c|c|c|c|c|c|c|c|}
\hline & & $\mathrm{k}$ & & & & & & \\
\hline Method & Statistic & -3 & -2 & -1 & 0 & 1 & 2 & 3 \\
\hline Data & $\operatorname{corr}\left(h_{t},(y / h)_{t-k}\right)$ & -0.342 & -0.363 & -0.187 & -0.144 & 0.475 & 0.470 & 0.346 \\
\hline \multirow[t]{2}{*}{ ISTC Model } & $\operatorname{corr}\left(h_{t},(y / h)_{t-k}\right)$ & 0.011 & 0.011 & 0.007 & -0.014 & -0.044 & -0.050 & -0.052 \\
\hline & (s.e.) & $(0.322)$ & $(0.280)$ & $(0.230)$ & $(0.364)$ & $(0.208)$ & $(0.251)$ & $(0.288)$ \\
\hline Data & $\operatorname{corr}\left(h_{t}, w_{t-k}\right)$ & 0.355 & 0.452 & 0.447 & 0.328 & -0.040 & -0.390 & -0.57 \\
\hline \multirow[t]{2}{*}{ ISTC Model } & $\operatorname{corr}\left(h_{t}, w_{t-k}\right)$ & 0.011 & 0.011 & 0.007 & -0.014 & -0.044 & -0.050 & -0.052 \\
\hline & (s.e.) & $(0.322)$ & $(0.280)$ & $(0.230)$ & $(0.364)$ & $(0.208)$ & $(0.251)$ & $(0.288)$ \\
\hline
\end{tabular}

\section{Conclusions}

We introduce investment-specific technological change into an otherwise standard real-businesscycle setup with a government sector. We calibrate the model to Bulgarian data for the period following the introduction of the currency board arrangement (1999-2018). We then investigate the quantitative importance of investment-specific technology shocks for cyclical fluctuations in Bulgaria, and compare the results to a setup where cycles are driven by shocks to total factor productivity only. We find that the model with ISTC shocks matches Bulgarian data better than the standard model driven by changes to total factor productivity only. The ISTC process is thus a better candidate for a a "technology shock generation process," at least in the Bulgarian context.

\section{References}

Arias, A., Hansen, G. and Ohanian, L. (2007) "Why have business cycle fluctuations become less volatile?" Economic Theory, 32(1): 43-58.

Bakhshi, H. and Larsen, J. (2005) "ICT-specific technological progress in the United Kingdom," Journal of Macroeconomics 27: 648-669. 
Basu, S., Fernald, J. and Shapiro, M. (2001) "Productivity growth in the 1990s: technology, utilization, or adjustment?" Carnegie-Rochester Conference Series on Public Policy 55: 117-165.

Baxter, Marianne and Robert King. 1993. "Fiscal policy in general equilibrium," American Economic Review 83: 315-334.

Bulgarian National Bank. 2019. Bulgarian National Bank Statistics. Available on-line at www.bnb.bg. Accessed on July 21, 2019.

Canova, Fabio. 2007. Methods for Applied Macroeconomic Research. Princeton University Press: Princeton, NJ.

Carlaw, K. and Kosempel, S. (2004) "The sources of total factor productivity growth: Evidence from Canadian data," Economic Innovations and New Technology 13: 299-309.

Cogley, Timothy and James Nason. 1995. "Output dynamics in Real-Business-Cycles," American Economic Review 85(3): 492-511.

Cummins, J.G. and Violante, G.L. (2002) "Investment-specific technical change in the U.S. (1947-2000): Measurement and macroeconomic consequences," Review of Economic Dynamics 5(2): 243-284.

Fisher, J. (2006) "The dynamic effects of neutral and investment-specific technology shocks," Journal of Political Economy 114(3): 413-451.

Gordon, R. (1990) The measurement of durable goods prices. University of Chicago Press: Chicago, IL.

Greenwood, J., Hercowitz, Z., and Huffman, G. (1988) "Investment, capacity utilisation 
and the real business cycle," American Economic Review 78(3): 402-417.

Greenwood, J., Hercowitz, Z., and Krusell, P. (1997) "Long-run implications of investmentspecific technological change," American Economic Review 87(3): 342-362.

Greenwood, J., Hercowitz, Z., and Krusell, P. (2000) "The role of investment-specific technological change in the business cycle," European Economic Review 44(1): 91-115.

Hodrick, Robert and Edward Prescott. 1980. "Post-war US business cycles: An empirical investigation." Unpublished manuscript (Carnegie-Mellon University, Pittsburgh, PA).

Justiniano, A. and G. Primiceri (2008) "The time varying volatility of macroeconomic fluctuations," American Economic Review 98(3): 604-641.

Justiniano, A., Primiceri, G. and Tambalotti, A. (2011) "Investment Shocks and the Relative Price of Investment," Review of Economic Dynamics 14(1): 101-121.

Kiley, M. (2001) "Computers and growth with frictions: aggregate and disaggregate evidence," Carnegie-Rochester Conference Series on Public Policy 55: 171-215.

Martinez, D., J. Rodrigez and Torres, J.L. (2008) "The productivity paradox and the new economy: The Spanish case," Journal of Macroeconomics 30(4): 1169-1186.

Martinez, D., J. Rodrigez and Torres, J.L. (2010) "ICT-specific technology change and productivity growth in the US: 1980-2004," Information Economics and Policy 22(2): 121-129.

Molinari, B., J. Rodrigez and Torres, J.L. (2013) "Information and Communication Technologies over the Business Cycle," The B.E. Journal of Macroeconomics 13(1): 933-963.

National Statistical Institute. 2019. Aggregate Statistical Indicators. Available on-line at www.nsi.bg. Accessed on July 21, 2017. 
Pakko, M.R. (2005) "Changing technology trends, transition dynamics, and growth accounting," The B.E. Journal of Macroeconomics, Contributions 5(1), Article 12.

Rodriguez, J. and Torres, J.L. (2012) "Technological sources of productivity growth in Germany, Japan, and the U.S.," Macroeconomic Dynamics 16(1): 133-156.

Rotemberg, Julio and Michael Woodford. 1996b. "Real-Business-Cycle Models and the Forecastable Movements in Output, Hours, and Consumption," American Economic Review, 86: 71-89.

Torres, J.L. (2013) Introduction to Dynamic Macroeconomic General Equilibrium Models. Vernon Press: Malaga, Spain.

Vasilev, A. (2017a) "Business Cycle Accounting: Bulgaria after the introduction of the currency board arrangement (1999-2014), European Journal of Comparative Economics, 14(2): 197-219.

Vasilev, A. (2017b) "A Real-Business-Cycle model with efficiency wages and a government sector: the case of Bulgaria," Central European Journal of Economics and Econometrics, 9(4): 359-377.

Vasilev, A. (2017c) "A Real-Business-Cycle model with reciprocity in labor relations and fiscal policy: the case of Bulgaria," Bulgarian Economic Papers BEP 03-2017, Center for Economic Theories and Policies, Sofia University St. Kliment Ohridski, Faculty of Economics and Business Administration, Sofia, Bulgaria.

Vasilev, A. (2017d) "VAT Evasion in Bulgaria: A General-Equilibrium Approach," Review of Economics and Institutions, 8(2): 2-17.

Vasilev, A. (2017e). "Progressive taxation and (in)stability in an exogenous growth model 
with an informal sector," Journal of Economics and Econometrics 60(2): 1-13.

Vasilev, A. (2016a). "Progressive taxation and (in)stability in an endogenous growth model with human capital accumulation," Journal of Economics and Econometrics 59(2): 1-15.

Vasilev, A. (2016) "Search and matching frictions and business cycle fluctuations in Bulgaria," Bulgarian Economic Papers BEP 03-2016, Center for Economic Theories and Policies, Sofia University St. Kliment Ohridski, Faculty of Economics and Business Administration, Sofia, Bulgaria.

Vasilev, A. (2015a) "Welfare effects of flat income tax reform: the case of Bulgaria," Eastern European Economics 53(2): 205-220.

Vasilev, A. (2015b) "Welfare gains from the adoption of proportional taxation in a generalequilibrium model with a grey economy: the case of Bulgaria's 2008 flat tax reform," Economic Change and Restructuring, 48(2): 169-185.

Vasilev, A. (2009) "Business cycles in Bulgaria and the Baltic countries: an RBC approach," International Journal of Computational Economics and Econometrics, 1(2): 148-170. 